\title{
The Optimization of Packaging System Process Parameters Using Taguchi Method
}

\author{
I.O. Fagbolagun and S.A. Oke*
}

\begin{abstract}
Packaging systems constitute substantially to product cost, its safety, and optimization. Unfortunately, no previous optimization studies have examined the packaging system in a bottling process plant for the unique, developing country environment. Consequently, the Taguchi method is applied to optimize a process plant's packaging system in a Nigerian plant's real-life situation. Optimal combinations of packaging system parameters that minimize product waste are created. An $\mathrm{L}_{4}\left(2^{3}\right)$ Taguchi orthogonal array was selected to analyze the data, and signal-to-noise ratios were computed for each experiment's run. Since the aim was to minimize beer waste, the 'the-smaller-the-better' signal-tonoise ratio was chosen in the analysis. $\mathrm{S} / \mathrm{N}$ ratio plots revealed the optimum settings to obtain minimal product waste, namely, $A_{2}, B_{1}$, and $C_{2}$ from the main effects plot for signal-to-noise ratios. A two-way ANOVA was performed on the significant factors to determine their percentage contributions to the response (product waste). Through Taguchi's innovative approach, the feasibility of optimizing the packaging process parameters was demonstrated and validated.
\end{abstract}

Keywords: Taguchi method, signal to noise ratio, orthogonal array, optimal setting, optimization.

Article Info: Received September 22, 2020; Revised October 25, 2020; Accepted November 29, 2020.

\section{INTRODUCTION}

\subsection{General}

Previous studies have identified packaging plays a significant role in attracting customers' attention and affecting their product choices (Silayoi and Speece, 2007; Karimi et al., 2013; Heide and Olsen, 2017; McMillin, 2017; Aerts and Smits, 2017; Fang et al., 2017), purchase intentions and consumers decisions (Verbeke et al., 2005; Grobbel et al., 2008). Consequently, appearance, color, and quality are critical properties of bottling products (Renerre and Labadie, 1993). This necessitates the design of packages that best portray these crucial properties. Notwithstanding, these attributes' optimization is desired (Sibalija et al., 2011; Sankaran et al., 2015). Process manufacturing plants have in a long time recognized optimization as a necessary requirement for progress (Lindeke and Liou, 1989; Park et al., 2011). It is ubiquitous in and by process plants that optimization is modeled, analyzed, and practically employed. The process plant opens up its machines, employees, and processes to a diverse range of optimization in man-hour losses, yield losses, losses due to quality defects and reworks, breakdowns, and lost machine hours. Accordingly, establishing optimization and achieving how to tackle it in packaging process plants has emerged as critical to modern scientific control in recent times.

Packaging research, nonetheless, is restricted in its capability to answer the question as to how process plants do and should treat optimization of processes since it has the shortcoming of recognizing and addressing the associated process parameters for the Nigerian situation with unique economic parameters, distinct workforce culture in workplaces and the perceptions of managers (system controllers), concerning prioritizing resource allocations (Renerre and Labadie, 1993; Silayoi and Speece, 2007; Zagloel and Al-Aina, 2009; Steenis et al., 2017). The packaging research in Nigeria failed to address the optimization

\footnotetext{
S.A. Oke* is with the Department of Mechanical Engineering, University of Lagos, Nigeria (email: sa_oke@yahoo.com).

* Corresponding author
} 
I.O. Fagbolagun and S.A. Oke

challenge in several ways. First, packaging researchers have not tackled what implications arise due to a process plant being located in a continuously changing economic situation. The governing theories of business survival have deviated from the norm, as suggested by economic experts. In this instance, specialized knowledge needs to be built by testing theories in several diverse manners and on a wide array of process plant determinants, such as employees, machines, processes, and finance. Others are availability, speed, and quality of the system's outputs. Research, which fails to account for optimization's influence, lacks the potential of explaining why process key variables showcase outcomes of particular thresholds or why it could be challenging to achieve specific set targets by the system's regulators. Second, studies have reported that the process industry has been built up for most components in the stream of overall system optimization, involving raw materials processing, production, maintenance, packaging, and marketing. Nevertheless, the packaging system is saddled with diverse operational and non-operational difficulties, dictated by whether the goal, in this instance, is to control the process for optimization on issues that could emerge in the foreseeable future, are occurring presently, or those that built up in the history of the process plant.

This paper addresses the issue of optimization of the packaging process plant parameters. Drawing on the innovative Taguchi's methodical approach that permits this study to abandon the traditional experimental design techniques, which are often difficult, expensive, and complicated, and often require a tremendous amount of experimental trials, especially with the growth in the number of process variables, this investigation embraces the Taguchi method, which will require less computational time, cost less and be easy to use. For instance, in the packaging process, the engineer is expected to use the acquired skills over the years in bringing the best to the packaging system. The engineer should use known techniques, processes, and enhanced skills to optimize its total brewery enhancement and plant accomplishment, implementing a safe and technical method to every phase of his/ her role. Unfortunately, pursuing the plant's continuous improvement through waste reduction is challenging. There is a changing profile of workers in the packaging department under the control of the packaging engineer. The operators in the packaging section, for instance, have high turnover, and this makes it also expensive and difficult to gather their historical performance data for future continuous improvement programs. Data on operators' skill level, work culture, relationship with peers, and other useful data are the ingredients of a continuous improvement program that the packaging engineer may find costly, challenging, and complicated to manage in the face of continually changing operators' attributes in the packaging department. The Taguchi innovative approach permits the opportunity to determine the significant factors influencing quality characteristics, product waste for the current investigation (Gong and Kao, 1997). Taguchi's orthogonal array's tremendous ability is exploited, in which a small number of experiments can be designed, requiring a small number of experimental runs, saving time, minimizing experimental costs, and discovering significant factors quickly.

The first phase of Taguchi's methodical implementation in the packaging process plant is the viewpoint of specifying the objective through a clear statement of what the packaging manager intends to achieve, with a perspective to understanding the effects of the specified four packaging parameters, with an attempt to determine the optimum factor combination to minimize product waste in the process plant. The second phase of Taguchi's approach relates to the identification of the quality characteristic of interest. The parameter optimized is often referred to as the quality characteristic or the response or the output, and it is product waste in this study. Third, the Taguchi method is to identify the control factors and determine their set levels to achieve the optimal output. In this phase, from the data collected, the control factors and noise factors are carefully selected. Control factors are those, which are under the direction and monitoring of the system analyst. Noise factors, on the other hand, must be controllable during the experimental process. The levels chosen are rooted in the required factors and the range of the process.

Fourth, the Taguchi method is applied to design the experiments and runs. Experiments are performed by running the set of noise settings when linking the control parameters. Using the Minitab 16 software, Taguchi's design (orthogonal array) was created, given the desired factor and level settings. The ratio is an evaluation of the accomplishment to build up products that are insensitive to variations (Mehat et al., 2014). Fifth, Taguchi's method has the viewpoint of analyzing data using Taguchi's orthogonal array, determination of signal-tonoise ratios for each run of the experiment, and plots are made. Here, Taguchi's experiments utilize mainly a two-phase optimization process, notably, to apply the signal-to-noise ratio to establish the control factors, which minimizes variability. The next is to establish the control variables that change the mean to target and have a little or negligible influence on the signal-to-noise ratio. Therefore, the signal-to-noise ratio appraises the response value variation in association with the target value subject to several noise factor environments. The statistical software, Minitab 16, offers signal-to-noise $(\mathrm{S} / \mathrm{N})$ ratios hinged on the experiment's objective: larger-is-better, nominal-is-best, and smaller-is-best.

\subsection{Problem definition and objective specification}

A considerable amount of effort has been made in practice and research to attain the most effective operational status in bottling process plants' packaging system. Basically, when the factory receives orders for large-scale bottling supplies, the marketing manager liaises with the managers in production, purchasing, supplies, and the accountant and the packaging manager. In conjunction with the human resources manager, the 
packaging manager appraises 'the organization's available manpower to estimate the labor hours needed to meet the product's needs. The packaging manager also evaluates the number of packaging materials needed as well as the number of input materials and the expected waste levels. The outcome of the packaging manager's effort is an intuitively-determined quantity of products (beer) issued the filler, possible quantities of hectolitres into the FBS, and an estimate of the number of creates needed. This is not an accurate set of data as the variance is usually enormous, and sometimes unreasonably, estimates must have been made. The problem of appraising these parameters to high precision must be addressed scientifically with practicallyoriented models. The most reasonable solution could be obtained when Taguchi's method is applied to optimize the parameters. This has not been addressed. A correct solution also has not been obtained so far in practice and the literature concerning packaging and optimization. The aim of a competent representation should be to associate the number of products, the nectolithe of liquid used, and the number of creates required and hence calculate the optimal quantities of these parameters and provide the most acceptable quantities that are practically relevant.

Most packaging systems are highly automated and are influenced by the many process parameters. This can often lead to high production costs and long packaging time (Mehat et al., 2014). However, optimization of packaging systems can be cost and time effective. In optimization, the design objective can be cost-reduction or maximization of the production process's efficiency given a set of parameters. As a result of improvement in technology, as well as meeting market demand, it has become necessary for plants often to enhance their packaging systems and processes for better quality. Therefore, engineers often are employed to decide what methods are best to obtain optimum parameter settings (Xydas et al., 2005). Generally, many optimization tools exist, some of which are: Grey relational analysis, mathematical models, artificial neural networks, response surface methodology, Taguchi methods, casebased reasoning, and non-linear modeling. This research paper focuses on applying the combination of the Taguchi method and ANOVA to optimize packaging parameters. The Taguchi method is often used in industries in place of the cumbersome trial-and-error method, which consumes time and money and often requires many experimental runs (Jou et al., 2014).

In contrast, the Taguchi method helps obtain the optimum parameter value from the stated factor level with few experimental runs and fewer times by reducing noise factors' variability (Jou et al., 2014). Taguchi method employs robust design to obtain the optimum parameters among a set of noise factors affecting the packaging system. The need to determine the control factors which will minimize variations in the packaging of the product, and obtain the optimum parameter setting which will minimize beer wastes, has been a major concern for manufacturers (Li et al., 2002). Therefore, this paper applies the Taguchi method and ANOVA principles to find the optimal packaging parametric combinations that will minimize wastage of products during packaging.

The study's goals are to identify the control factors to minimize product waste during packaging and obtain optimum factor combinations that will drastically minimize beer loss in packaging. This research study covers the area of packaging in process plants, paying keen attention to the optimization of packaging process parameters. The study aims at finding the optimal factor setting to reduce product wastage during packaging. A case study of a packaging system in a brewery in Nigeria is considered, obtaining control parameters needed to design the experiments. This study is aimed at improving the packaging system of a bottling company using the Taguchi method. This study's success will expose innovative engineering solutions to the problem of packaging, especially in the area of maintenance and product quality. Optimization of packaging system results in less environmental impact (that is, low waste and less transport), minimized operational costs, at the same time, enhancing product quality in process plants. Identifying the noise factors will limit packaging process variations, which can be adopted by a significant process, packaging, and recycling companies. Quality maintenance through reduced variation is another advantage of this study. Lastly, a reduction in process cost and time will increase product yield and profit maximization.

\section{LITERATURE REVIEW}

In this section, a review of the major contributions in process optimization in manufacturing plants is compiled as related to this research. Over the years, much work has been done to optimize manufacturing processes to improve quality and cost reduction (Dhoke, 2016; Casalino et al., 2016; Jiang et al., 2016; Nyemba and Mbohwa, 2017; Jin et al., 2017). Optimization of processes is usually executed through process parametric analysis gathered from designed experiments performed on the actual industrial process (Sibalija et al., 2011). Various statistical tools are adopted to design experiments to achieve optimal factor settings such as Taguchi, response surface methodology, grey-relational analysis, and others are employed instead of trial-anderror methods. The trial-and-error approach wastes time and incurs more costs (Dhoke, 2016). This section, therefore, considers the works of significant researchers under the aforementioned methods.

\subsection{Single optimization method}

This section contains significant reviews of works using mainly the Taguchi design method as the major optimization tool to enhance single quality characteristics of manufacturing process parameters. It is a powerful optimization tool developed in 1949 by Dr. Genichi Taguchi (Jou et al., 2014). This expert desired to lessen the number of experiments required to study problems in developing communication systems (Jou et al., 2014). Lindeke and Liou (1989) discussed the nine 
I.O. Fagbolagun and S.A. Oke

well-explained Taguchi method steps to aid engineers in design, problem identification, analysis, team building, and problem study. Tsai and Mort (1996) performed Taguchi experiments to analyze the link between performance and operational variables in noncontinuous scheduling problems. The results showed that forming complex systems, assessment, and improvement of operating conditions are simultaneously accounted for. Anthony (2001) adopted Taguchi quality loss function analysis in product performance and quality. Kang and Hadfield (2001) used Taguchi methods to optimize a lapping machine's lapping parameters and showed that the optimum lapping conditions corresponded to high load and high paste concentration with $60 \mu \mathrm{m}$ diamond units. Sukthomya and Tannock (2005a) used the Taguchi design of experiments to determine the best neural network variable setting using the backpropagation formula.

Sukthomya and Tannock (2005b) used the Taguchi method, which picks the designed data from historical experimental records in aerospace production data. Kirby (2006) enhanced the surface roughness of a CNC turning operation using the Taguchi method to identify the control factors and noise variables. Patnaik et al. (2008) studied a composite system's erosion behavior that contained thermoplastic polyester resin strengthened with $\mathrm{SiC}$ and E-glass particles using Taguchi design. The genetic algorithm helped to give an optimum level of factors. Kamaruddin et al. (2010) used Taguchi robust designs to improve a plastic tray's shrinkage qualities made from two polymers. The optimal parameter factor settings showed the shrinkage quality as low at a minimal melting temperature, significantly elevated pressure of injection, minimal holding pressure, cooling, and lengthy holding time. Wazed et al. (2010) used the Taguchi method to determine the optimal batch size in the bottleneck area of a components and machinery process subject to commonalities, uncertainties, and capacity limitation.

Karna et al. (2012) used the Taguchi method to improve the quality and the performance output of a process. Athreya and Venkatesh (2012) used the Taguchi method to optimize the process factors affecting surface roughness of facing process on a lathe machine. Also, Pattnaik et al. (2013) studied the impact of injection process factors on the dimensional stability of wax patterns produced via investment casting using L9-Taguchi orthogonal array. Moreover, Ramakrishnan and Arumugam (2013) used the Taguchi method to check the maximum cooling tower's effectiveness using expanded mesh packing as a cooling tower with the counter flow. An $\mathrm{L}_{27}$ orthogonal array was used to design Taguchi experiments. Patyal et al. (2013) optimized operations in India's chemical industry using the optimal settings that were defined by using the Taguchi method for the loss-on-ignition. The outcome of Taguchi's $\mathrm{L}_{9}$ experiment showed that the loss-onignition was low at $15 \%$, with a corresponding increase in percentage borate matter at $45 \%$. Al-Refaie et al. (2013) discussed the optimization of multiple fuzzy responses by applying fuzzy regression and desirability function in Taguchi methodology. Pour, and Moghadam (2014) used the Taguchi approach in the nano-calcium carbonate optimization to determine the best manufacturing level. Experimental results showed that the utmost echelon of process factors was a gas flow rate of 20 liters/minutes, 9 liters/minutes of solution flow rate, and a solution concentration of $70 \mathrm{~g} /$ litres. The production process rate was also improved by $168 \%$ by applying the best level of process variables compared to the mean value from experimental results.

Furthermore, Reddy et al. (2015) used the Taguchidata envelopment analysis-based ranking multiresponse optimization method to investigate the electric discharge machining of PH17-4 stainless steel. Candan and Yazgan (2015) used Taguchi's orthogonal array with ANOVA to investigate the FMS scheduling problem to reduce the problem is elapsed time. Chandrasekar et al. (2015) used Taguchi orthogonal array method to enhance the process variables required to prepare peanut chutney. After a 40-day experimental period, the free fatty acid content was estimated between $0.44-0.23 \%$ of oleic acid, peroxide value of $28.7-51.5$ $\mathrm{meq} / \mathrm{kg}$, and phenolic content of $1.75-4.7 \mathrm{mg} / \mathrm{g}$ were reported. Likewise, treatments were optimized, with the best treatment being that of $\mathrm{A}_{2}$ vinegar at $10 \%, \mathrm{~B}_{1}$ glass bottle, and $\mathrm{C}_{1}$ refrigeration temperature between $5 \pm 2^{\circ} \mathrm{C}$. Confirmatory tests were performed. Furthermore, Dwiwedi and Kumar (2015) optimized the process parameters for polypropylene material in injection molding using the Taguchi method. Kumar and Kumar (2015) used the Taguchi method to optimize the HDPE material's process variables in extrusion blown film machinery. In the analysis, melting point temperature, extrusion speed, the pressure of extrusion, and winding speed were considered. Experiments were performed using orthogonal arrays, tensile strength was measured, and the optimum factors were obtained from graphs plotted. More recently, the Taguchi method has been applied to composite fabrication (Ganesan and Kaliyamoorthy, 2020), wastewater process optimization (Souza et al., 2020), and pod production (Ishrat et al., 2020).

\subsection{Hybrid optimization methods}

This section considers the combination of the Taguchi method with other methods to solve multiple quality optimization problems.

Chen and Hung (2006) examined the sensitivity of a four-bar function generator using the Taguchi-fuzzy based method to determine the average variations and maximum displacement variations of the function generator. Blackhall et al. (2006) combined Taguchi methods and texture profile analysis to optimize the food industry's biscuit process. They performed actual laboratory-based trials in a food company patterned to imitate a real industry-based experiment. Their approach successfully reduced the cost of experimentation and, consequently, can be recommended for full-scale production plants. Hung (2007) applied Taguchi methods with hybrid artificial 
intelligence methods to solve optimum parameters in wire bonds design for an ultra-thin scale CSP package. This improved the robustness design yield. Zagloel and Al-Aina (2009) optimized an industrial process using Taguchi design models to determine the optimal process factors. Data collected from a laminating machine in the packaging industry utilizing gram to represent quality response was employed to emphasize these methods. Chen et al. (2009) applied the principal component analysis and Taguchi method to study the impact of production tolerance and joint clearance on the dualpurpose functioning six-bar machine's quality. The response diagram with tables was finally analyzed to determine the main dimensions of the mechanism.

Sibalija et al. (2011) optimized the multiple-response type of process using historical data. These processes were designed using the Taguchi method, genetic algorithm, and human-made neural network to ensure optimal settings. They concluded that this approach was effective from the results analyzed. Chomsamutr and Jongprasithporn (2012) used Taguchi and response surface methodology to deduce the most prolonged tool life of medium carbon steel in other to make a comparison between cutting variables. The work considered three basic parameters: depth-of-cut, feed rate, and cutting speed during turning. The results showed that RSM's error was $0.07 \%$, but the cutting variables produced a tool life of 670.170mins. Therefore, the response value and tool life methods gave similar results. Mehat et al. (2014) integrated Taguchi design, grey-relational analysis, and physical component techniques. They used plastic gear to validate these methods. The hybrid optimization method generated plastic-molded gear with shrinkage minimized at values of $1.8 \%, 1.53 \%, 2.42 \%$ in tooth thickness, addendum, and dedendum circle, respectively. Integrating these methods drastically reduced shrinkage behavior and defects in plastic gear. Al-Refaie (2015) employed a weighted-additive model in fuzzy goal programming to optimize multiple Taguchi method responses. Four selected case studies that compared to other models provided more dependable optimal factor settings. Furthermore, Kumar et al. (2015) used grey-Taguchi methods to solve the problem. Input data of 81 sets from a milling sample that corresponds to a 3-level full factorial design of experiments are considered. The method accounted for four cutting factors: cutting speed, feed, and depth-ofcut in the axial direction with that in the radial direction. Results obtained showed that neural network factors are optimum under the following conditions: low mean square error, few numbers of iterations, and less experimental time, which gave a reduced computational and processing time. Of late, the Taguchi method has been combined with grey relational analysis for coating process optimization (Ustuntag et al., 2020). To optimize woven fabric parameters, the Taguchi method was amalgamated with grey relational analysis (Almetwally, 2020).

\subsection{Observations and limitations of related literature}

The contributed studies about packaging process parametric optimization are known to exhibit the following drawbacks, and the observed trends in literature are also subsequently itemized.

a. The process optimization domain is saturated with industrial-based applications, and such include shrinkage quality of plastic tray (Kamaruddin et al., 2010), surface roughness of a facing process, enhancement of process variables to prepare readyto-eat peanut dintney (Chandrasekar et al., 2015), high-density polyethylene material optimization in extrusion blown, film machinery (Kumar and Kumar, 2015), polypropylene material injection molding (Dwiwedi and Kumar, 2015), lapping parameters in a lapping machine (Kang and Hadfield, 2001), a four-bar function generator (Chen and Hung, 2006), biscuit production in the food industry (Blackhall et al., 2006).

b. Only one study was sighted on the packing industry (i.e., laminating machine) by Zagloel and Al-Aina (2009).

c. Worldwide locational studies have been mainly reported for developing countries such as India and Malaysia. However, the search did not produce even a study in the manufacturing domain's relevant area, particularly the packaging industry.

d. Many of the studies were reported on small scale real case studies. In contrast, fewer studies were conducted on medium scale industries, and very few were reported on large scale manufacturing industries. However, the current research focuses on large scale manufacturing industries.

e. Literature reports have clearly indicated that very little research has focused on optimizing Nigerian industries, which are examples of those in developing countries.

f. The majority of optimization models concerning processes could be broadly classified as single and combinatorial optimization models. While single models have considered the Taguchi method alone, combination models have amalgamated. Taguchi with fuzzy (Chen and Hung, 2006), fuzzy goal programming (Al-Refaie, 2015), grey relational analysis (Kumar and Pandey, 2015), hybrid artificial intelligence (Hung, 2007), neural network (Zagloel and Al-Aina, 2009), principal component analysis (Chen et al., 2009).

Among the various optimization techniques such as linear programming, dynamic programming, goal programming, and Taguchi technique, the Taguchi methodical (TM) framework provides extra desirable attributes. For instance, the TM framework is a clearcut, simple-to-operate tool for several packaging process subsystems, including the packaging process lines. Thus, the TM is an influential but straightforward instrument. A second strong advantage of why the current research prefers the TM to other optimization methods is that it is influential in confining the packaging process optimization project's capacity. In 
I.O. Fagbolagun and S.A. Oke

other words, the TM is highly favored to be used as a tool to establish the challenges faced in the packaging process from the group of data previously in existence. Furthermore, a strong and non-negligible fact is that the TM permits examining several various packaging process parameters devoid of unreasonably elevated quantities of scientific experimentations. In addition, minimum information is required from the packaging process to actualize the TM processing. It is clear to note that very little or negligible need for training exists in operating the optimization system using the packaging process and Taguchi's robust framework. Consequently, in the current research, the Taguchi technique was employed for optimization and emphasized. Furthermore, the company studied targets to produce brewed products to customer satisfaction in requirement levels, quality conformity, and the budgeted production cost. While pursuing this goal, the packaging engineer is expected to substantially influence utility costs, spares, labor costs, production, raw materials, rework, and quality. However, waste arises from non-optimal operations by the system operations due to inadequate filling speeds of fillers. Waste causes losses in labor cost and production figures, disproportional investment in spares, and overwhelming rework cost. To overcome this problem, a robust design method is essential for the packaging process. It is reasonable to apply such a method to improve the quality of the product and reduce waste. In this regard, the Taguchi method is a good fit to solve this problem. Hence, the Taguchi method is adopted to reduce waste arising from the packaging process workstations.

\section{RESEARCH METHODOLOGY}

This section explains systematically all the steps taken to carry out the optimization of the quality characteristic. The Taguchi method is first used to pick out factor(s), which tend to influence the quality characteristic or response significantly. It is often termed the fractional factorial method as little experimental data needs to be analyzed to improve product quality effectively. The main tools used are signal-to-noise $(\mathrm{S} / \mathrm{N})$ ratio and orthogonal arrays. The smaller-the-better signal-tonoise ratio is used since the main aim is to minimize the hectolitres of beer waste lost. ANOVA analysis is often applied after the Taguchi method to determine each input parameter's significance on the final output to be optimized. The percentage composition of each input factor is often measured as well.

\subsection{Research procedures}

The proposed approach involves the following procedures:

Step 1: Identify the factors and levels.

Step 2: Compute the signal to noise ratios.

Step 3: Develop the response table.

Step 4: Obtain optimal parametric setting.

The criteria for computing the signal-to-noise ratios are as follows:
Larger is better: $S / N=-10 \log \frac{1}{n} \sum\left(\frac{1}{y^{2}}\right)$

Nominal is best: $S / N=-10 \log \sigma^{2}$

Smaller is better: $S / N=-10 \log \frac{1}{n} \sum\left(y^{2}\right)$

where $n$ is the sample size, $y$ is the beer waste in that run and $\sigma^{2}$ is the variance of the distribution.

\subsection{Why is this method?}

The packaging process factors could be implemented using the present system of operations in the plant but in a trial and error approach wherein system managers are unaware of the most advantageous process parameters to utilize. They are also ignorant of what form to combine these factors. Nevertheless, the contemporary industrial economy places significant pressure on the system manager for the smart, efficient, and costeffective approach to managing the most desired packaging system. At the same time, the government's safety and environmental concerns have to be taken into account. Thus, proactive steps about optimization of the packaging system have to be taken by the packaging manager. To achieve this, Taguchi optimization may need to be implemented. In this research, a detailed examination of the Taguchi scheme for obtaining the most favorable factor for the combination of parameters in the packaging system has been utilized. The optimization proceeds to aid efficient as well as the costeffective working of the packaging system.

Traditional experimental design techniques are often difficult, expensive, and complicated. They often require a significant number of experimental runs, especially with an increase in the number of process variables. Hence, it became necessary to develop a method that will require less computational time, cost less, and be easy to use. One such method is the Taguchi method. For these reasons, the Taguchi method was chosen for the analysis to determine the significant factors influencing the quality characteristics, in this case, beer waste. With Taguchi's orthogonal array, a small number of experiments can be designed requiring few experimental runs, saves time, minimizes experimental costs, and discovers significant factors quickly.

\section{RESULT AND DISCUSSION}

This section collates all the results from analyzing the data collected using the combined Taguchi and Response surface methodology optimization tools. Typical data from a bottling industry's packaging lines were collected and analyzed to determine the factor settings to yield the least hectolitres of beer waste. Hence, four factors, namely, beer-filled into the filler (HL), total time available (hrs.), hectolitres into FBS, and crates into FBS, were considered to measure their influence on beer waste. Taguchi's smaller-the-better signal to noise ratio and ANOVA were used to screen the key factors that minimized the industry's beer waste 
(this is the same as the variable (D). However, a significant aspect of this waste is generated through the filling machine bear is filled into bottles and concurrently pressurizes for preservation. Too high of the filler's filling speed generates higher pressure than necessary, possibly causing cracks at the top of the bottle and making them reject if the speed is too low during production hours.

\subsection{Taguchi methodology}

\subsubsection{Experimental factors and levels}

Four factors were selected that affected the beer waste from the packaging process. Maximum and minimum values of readings were recorded for each factor. Hence, a factor level setting of two was applied, as shown in the Table 1 .

In Table 1, two values are obtaining the minimum and maximum for each level. A fairly robust approach is to collect such data over one year and then use the mean quarterly values to yield four levels. However, this was not possible in this case as the production engineer imposes some restrictions on the release of the data. In this instance, the best information provided is the minimum and maximum values of the parameters. So, it was determined to convert them to levels.

In this study, three lines of production are present. However, each production line has an identical and independent machine specification. These products are contained in glass. The packaging manager for these lines controls other workers, including the mechanical engineers. Each of them owns the maintenance in a line and has the responsibility of sharing his/her expertise and experience with other engineers managing the other lines.

Notwithstanding, the mechanical engineer controls craftsmen and technical operators with a diversity of skills. However, the mechanical engineer is expected to engage these subjects, lead and direct them towards the plant's goals while engaging in shift or day duties. In the production lines, the mechanical engineer's participation is also required in offering suggestions to the maintenance planner. The planner's function is to ascertain the scoping, resourcing, achievement, and appraisal of maintenance tasks for the various lines. All the key personnel in the packaging's overall goal is to drive packaging efficiency and accomplishment by actualizing engineering and management skill advancement and instruction. It should be noted that the total time available is taken as the noise variable. It is not included in the internal ray design, i.e., there is no external array.

\subsubsection{Design of experiments}

Table 2 shows the L4 orthogonal array and the associated experimental results for the beer waste designed with Taguchi DOE. Integers 1 and 2 represent factor levels. These are coded levels for the design of the experiment.

\subsubsection{Analysis of control factors}

In Taguchi methodology, the term 'signal' refers to the desirable value (mean) for the response, whereas the term 'noise' represents the undesirable value for the response. $\mathrm{S} / \mathrm{N}$ ratio is utilized to measure the deviations of the quality characteristics from the desired value. Since the study aims to minimize the quantity of beer waste produced, a smaller is better $\mathrm{S} / \mathrm{N}$ ratio was used. The objective function, therefore, is smaller is better, and the $\mathrm{S} / \mathrm{N}$ ratio for this is given in Equation (3).

Analyses of the effects of each control factor (A, B, C) on beer waste were performed with an $\mathrm{S} / \mathrm{N}$ response table, using the Minitab 16 software package. Table 3 shows the orthogonal array and experimental results for beer waste with the calculated $\mathrm{S} / \mathrm{N}$ ratios. The $\mathrm{S} / \mathrm{N}$ response table for the beer waste is presented in Table 4 . It shows the calculated $\mathrm{S} / \mathrm{N}$ ratios of control factors at each level. The control factor with the most significant influence was determined based on the delta's value, as shown in Table 4.

It should be noted that in Taguchi designs, the delta is the difference between the maximum and minimum mean response across levels of a factor. The higher the value of delta computed, the more influential the factor. The factors and their corresponding interactions were sorted according to the values of the delta.

Table 1. Experimental variables and levels for Packaging line 3

\begin{tabular}{|c|l|c|c|c|}
\hline \multirow{2}{*}{ Code } & \multirow{2}{*}{ Experimental variables } & \multicolumn{3}{|c|}{ Levels in coded form } \\
\cline { 3 - 5 } & & 1 & 2 & Units \\
\hline A & Beer issued into filler & 5697.00 & 25693.00 & HL \\
\hline B & Hectolitres into FBS & 5020.38 & 23604.55 & HL \\
\hline C & Crates into FBS & 69728.00 & 298031.00 & Units \\
\hline D & Total time available & 84.00 & 300.00 & Hrs \\
\hline
\end{tabular}

Table 2. Experimental design using $\mathrm{L}_{4}$ orthogonal array and response values

\begin{tabular}{|c|c|c|c|}
\hline $\begin{array}{c}\text { Beer into } \\
\text { filler }\end{array}$ & $\begin{array}{c}\text { Crates into } \\
\text { FBS }\end{array}$ & $\begin{array}{c}\text { Hectolitres into } \\
\text { FBS }\end{array}$ & $\begin{array}{c}\text { Beer } \\
\text { waste }\end{array}$ \\
\hline 1 & 1 & 1 & 2588.91 \\
\hline 1 & 2 & 2 & 1027.03 \\
\hline 2 & 1 & 2 & 676.62 \\
\hline 2 & 2 & 1 & 2088.45 \\
\hline
\end{tabular}


I.O. Fagbolagun and S.A. Oke

Table 3. Responses with calculated $\mathrm{S} / \mathrm{N}$ ratios

\begin{tabular}{|c|c|c|c|c|}
\hline Beer in filler & Crates into FBS & Hectolitres into FBS & Beer waste & S/N ratio \\
\hline 1 & 1 & 1 & 2588.91 & -68.2623 \\
\hline 1 & 2 & 2 & 1027.03 & -60.2317 \\
\hline 2 & 1 & 2 & 676.62 & -56.6069 \\
\hline 2 & 2 & 1 & 2088.45 & -66.3965 \\
\hline
\end{tabular}

Table 4. S/N response table for the beer waste

\begin{tabular}{|c|c|c|c|}
\hline Level & Beer into filler & Crates into FBS & Hectolitres into FBS \\
\hline 1 & -64.25 & -62.43 & -67.33 \\
\hline 2 & -61.50 & -63.31 & -58.42 \\
\hline Delta & 2.75 & 0.88 & 8.91 \\
\hline Rank & 2 & 3 & 1 \\
\hline
\end{tabular}

Table 5. Optimum values of factors and their levels

\begin{tabular}{|c|c|}
\hline Parameter & Optimum value \\
\hline Beer into filler & 25,693 hectolitres \\
\hline Hectolitres in FBS & $5,020.38$ hectolitres \\
\hline Crates into FBS & 29,8031 stacks \\
\hline
\end{tabular}

From the response Table 4 , the beer waste (unit) is calculated from the optimal parametric setting, $\mathrm{A}_{2} \mathrm{~B}_{2} \mathrm{C}_{2}$, given in Table 5 as 25,693 hectolitres of beer into the filler, 5,0202.38 hectoliters in FBS, and 29,8031 crate into FBS. The parameter D is considered a noise variable.

From Tables 3 and 4, it can be deduced that the first factor which increases beer waste is the hectolitres into FBS, followed by the beer in the filler, and least is the packs of crates into the FBS. This is evident from the values of delta and the rank in Table 4. In addition to this, plots for the signal to noise ratios are shown in Figure 1. The best levels for each experimental factor could be deduced from these graphs with respect to Taguchi's 'the-smaller-the-better' performance characteristics. The factor levels equivalent to the highest signal to noise ratio were selected to optimize the objective. Figure 1 shows that the optimum setting to obtain minimal beer waste would require the combinations of control factors: $\mathrm{A}_{2}, \mathrm{~B}_{1}$, and $\mathrm{C}_{2}$ form the main effects plot for the signal to noise ratios. This means that the factors' optimal values and their levels can be deduced from the signal to noise plots of Figure 1 , respectively, and note that each linear graph's highest points is the best setting. Therefore, from $\mathrm{S} / \mathrm{N}$ ratio plots, the optimal combinations of the factors and their levels required to minimize the objective parameter or response (beer waste) are given in Table 5.

\subsection{Analysis of Variance (ANOVA)}

In this study, ANOVA was used to analyze the effects of the process parameters on the response. ANOVA is a statistical method used to determine the individual interaction of all control factors. Percentage distributions of each control factor are often used to measure the effects on the quality characteristics. ANOVA helps test the significance of all main factors and their interactions by comparing the mean square against an estimate of the experimental errors at a specific confidence level. Often, when the $p$-value calculated is greater than 0.05 , the related design parameter appears to have no significant effects on the quality characteristic. However, if the $p$-value is less than 0.05 , the factor significantly affects the optimized response.

The results for ANOVA analysis are shown in Table 6. Table 6 shows that hectolitres into FBS with a p-value of 0.032 , which is less than 0.05 , have the most statistically significant effect on the response variable. Hence, it contributes most to the volume of beer waste generated during the packaging process. Beer into the filler has a $p$-value of 0.111 . This is greater than 0.05 (95\% significance); hence its effect on the volume of beer waste generated is statistically non-significant. Thus, beer waste is mostly influenced by hectolitres (beer spills) into the FBS machine during the cleaning process. Therefore, it should be of importance for breweries to design their packaging systems to prevent to a large extent the occurrence of any wastage during packaging. Installation of inspection facilities should be invested to monitor the filling of beer in bottles and a proper crowning of beer bottles.

This article contributes to a novel manner by offering a new structure to analyze packaging process performance by examining significant parameters that impact the packaging process's performance. Also, it offers a rare cross-pollination of ideas by taking insights from three distinct areas of contemporary practice: the 


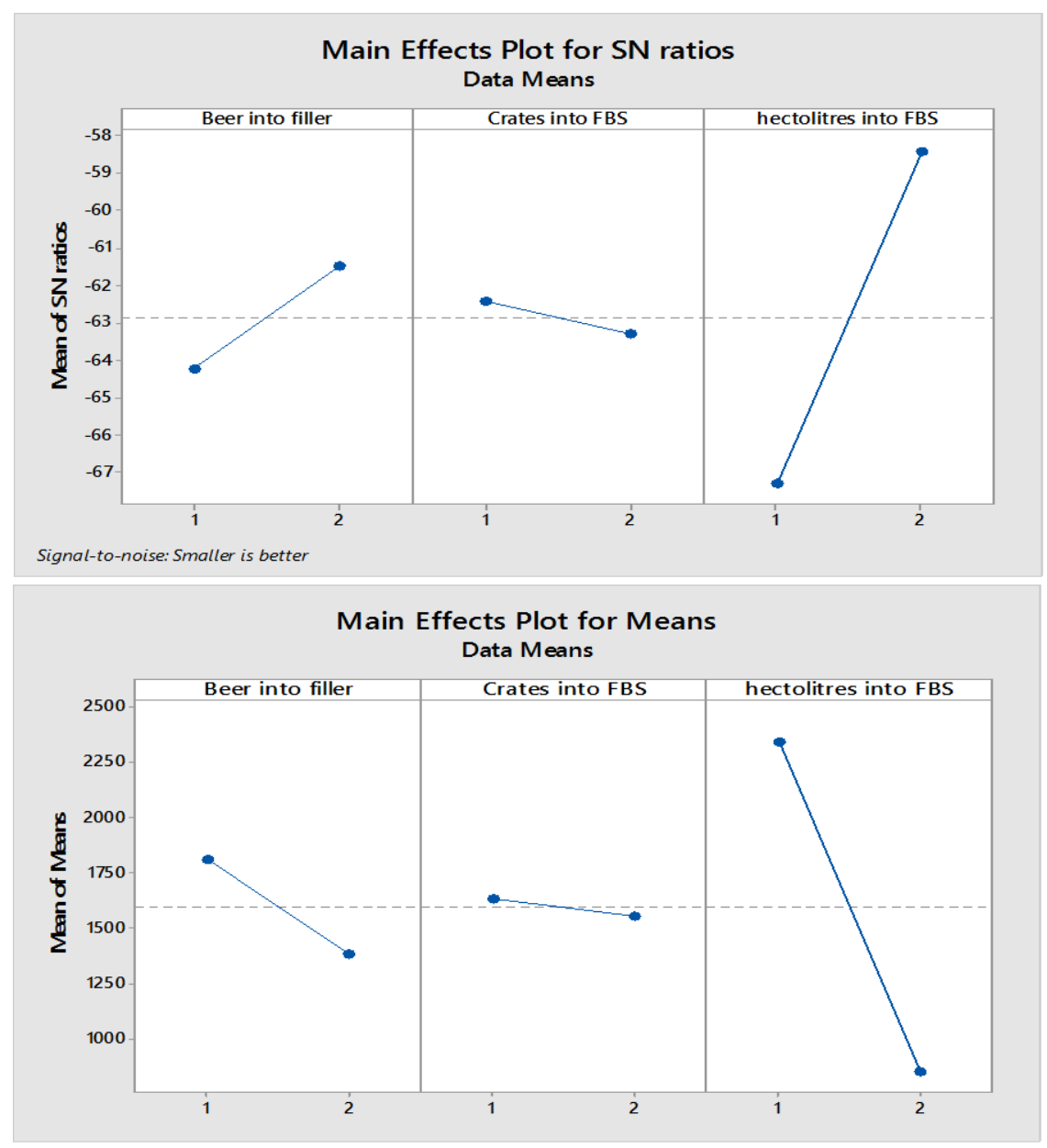

Figure 1: Main Effects plots for Signal to Noise ratios and means

Table 6. Two-way ANOVA analysis

\begin{tabular}{|l|l|l|l|l|l|}
\hline Source & DF & SS & MS & F & P \\
\hline Hectolitres into FBS & 1 & 2210738 & 2210738 & 392.76 & 0.032 \\
\hline Beer into filler & 1 & 180995 & 180995 & 32.16 & 0.111 \\
\hline Error & 1 & 5629 & 5629 & & \\
\hline Total & 3 & 2397361 & & & \\
\hline
\end{tabular}

product packaging process as relevant to food products packaging technology, the manufacturing process area that is concerned with the transformation of raw materials into finished goods, and the optimization area that deals with the utmost and most advantages values of resources to utilize. It exhibits implications for these three literature areas. At present, there is a vacuum in research. A large majority of studies have ignored the utility of optimization techniques and the tremendous advantages it offers to the community of researchers. There has been a heavy reliance on the packaging system's physical and chemical property parameters in decision-making and analysis concerning packaging process evaluation. The current study offers the advantage of the minimum possible use of a number of experiments to accomplish goals.

\section{CONCLUSIONS}

Minimizing the quantity of beer waste is often a concern for most breweries. It is necessary to drastically reduce beer loss via wastage, especially during the filling and crowning processes. Hence, the need for this research arose. In this study, the optimization of packaging system parameters was carried out by applying Taguchi method to obtain the optimal beer waste value. A proper investigation of the effects of the three parameters on the quality characteristic was achieved. In modeling the process, Taguchi $\mathrm{L}_{4}\left(2^{3}\right)$ orthogonal array was designed to run the experiments, thus, reducing the total number of performed tests. The ANOVA selection method was used to determine the input parameters' optimal values to achieve minimum beer waste as the output parameter. The optimal conditions were beer into the filler at level 2 , crates of 
I.O. Fagbolagun and S.A. Oke

bottles into FBS at level 1, and beer spills into FBS at level 2. Taguchi was successfully applied to determine the optimal combination of input factors to minimize waste, costs, and packaging time of beers, respectively.

This study has investigated an interesting area that has the potentials to expand to other areas, thereby making the study multi-area, which will account not only for the optimization aspect of the packaging process parameters but also serve as a financial control mechanism by installing a driver that brings consciousness, caution and judicious use of skills, time and materials to prevent waste. In this context, this research discusses the design of experiments for packaging using the Taguchi method to determine the optimal parametric setting for the process parameters while minimizing beer waste as a target set by the company. These results of the study assist in establishing areas that require more in-depth study. However, waste minimization has the financial aspect as the labor cost, production losses, losses due to disproportionate use of spares, raw materials cost, and utility costs, which work against the attainment of optimal levels of parameters. Consequently, a driver is needed that cuts across all these elements with which caution could be taken when the labor component of resources in the organization is working towards the system's goals. In this context, the introduction of an interest rate driver in future studies may profit the packaging research using the current work method. The proposed methodology will create consciousness in the labor force on the cautious and judicious usage of materials and skills to reduce wastage. This will make the model ideal for use when the organization wants to borrow money from financial houses. In this regard, the ability to pay back may be suggested by the model. Another aspect of future research relates to the exploration of some analysis of response surface methods. In this instance, essential insights into the optimal response value (response optimizer) and desirability value may be thoroughly discussed.

\section{REFERENCES}

Aerts, G., \& Smits, T. (2017), The package size effect: How package size affects young children's consumption of snacks differing in sweetness, Food Quality and Preference, 60, 72-80.

Almetwally, A.A. (2020). Multi-objective optimization of woven fabric parameters using Taguchi-Grey relational analysis, Journal of Natural Fibers, 17(10), 1468-1478.

Al-Refaie, A. (2015). A proposed weighted additive model to optimise multiple quality responses in the Taguchi method with applications, Proceedings of the Institution of Mechanical Engineers, Part E: Journal of Process Mechanical Engineering, 229(3), 168-178.

Al-Refaie, A., Rawabdeh, I., Jalham I., Bata, N., \& AbuAlhaj, R. (2013). Optimization of multiple responses in the Taguchi method using desirability function and fuzzy regression, Proceedings of the International MultiConference of Engineers and Computer Scientists 2013, 2, IMECS 2013, March 13 - 15, Hong Kong.

Anthony, J. (2001). Simultaneous optimisation of multiple quality characteristics in manufacturing processes using Taguchi's quality loss function, The International Journal of Advanced Manufacturing Technology, 17(2), 134-138.

Athreya, S., \& Venkatesh, Y.D. (2012). Application of Taguchi method for optimization of process parameters in improving the surface roughness of lathe facing operation, International Refereed Journal of Engineering and Science, 1(3), 13-19.

Blackhall, R.B., Ritchie, J.M., Baxter, L.F., \& Black, I. (2006). The novel combination of Taguchi methods and texture profile analysis applied to the optimisation of laboratory-based biscuit manufacturing, Proceedings of the Institution of Mechanical Engineers, Part B: Journal of Engineering Manufacture, 220(2), 273-293.

Candan, G., \& Yazgan, H.R. (2015). Genetic Algorithm parameter optimisation using Taguchi method for a flexible manufacturing system scheduling problem, International Journal of Production Research, 53(3), 897-915.

Casalino, G., Facchini, F., Mortello, M., \& Mummolo, G. (2016). ANN modeling to optimize manufacturing processes: the case of laser welding, IFACPapersOnline, 49(12), 378-383.

Chomsamutr, K., and Jongprasithporn, S. (2012). Optimisation parameters of tool-life model using Taguchi approach and response surface methodology, International Journal of Computer Science Issues, 9(1), 120-125.

Chandrasekar, V., Kannan, K., Priyavarshini, R., \& Gayathri, R. (2015). Application of Taguchi method in optimization of process factors of ready to eat peanut (Arachis hypogaea) Chutney, International Food Research Journal, 22(2), 510-516.

Chen, F.C., Tzeng, Y.F., Chen, W.R., \& Hsu, M.H. (2009). The use of the Taguchi method and principal component analysis for the sensitivity analysis of a dual-purpose six-bar mechanism, Proceedings of the Institution of Mechanical Engineers, Part C: Journal of Mechanical Engineering Science, 223(3), 733-741.

Chen, F.C., \& Huang, H.H. (2006). Taguchi-fuzzybased approach for the sensitivity analysis of a fourbar function generator, Proceedings of the Institution of Mechanical Engineers Part C: Journal of Mechanical Engineering Science, 220(9), 1413-1421.

Dhoke, M.V. (2016). Parametric optimization in turning 
using response surface methodology, Journal of Information, Knowledge and Research in Mechanical Engineering, 4(1), 714-719.

Dwiwedi, A.K.R., \& Kumar, S. (2015). Practical application of Taguchi method for optimization of process parameters in injection molding machine for PP material, International Research Journal of Engineering and Technology, 2(4), 264-268.

Fang, Z., Zhao, Y., Warner, R.D., \& Johnson, S.K. (2017). Active and intelligent packaging in meat industry, Trends in Food Science and Technology, 61, 60-71.

Ganesan, V., \& Kaliyamoorthy, B. (2020). Utilization of taguchi technique to enhance the interlaminar shear strength of wood dust filled woven jute fiber reinforced polyester composites in cryogenic environment, Journal of Natural Fibers, 17, 1-12.

Gong, C., \& Kao, I. (1997). Design for accuracy and repeatability for robots using Taguchi methods, Concurrent Engineering, 5(3), 263-277.

Grobbel, J.P., Dikeman, M.E., Hunt, M.C., \& Williken, G.A. (2008). Effects of packaging atmospheres on beef instrumental tenderness, fresh color stability, and internal cooked color, Journal of Animal Science, 86(5), 1191-1199.

Heide, M., \& Olsen, S.O. (2017). Influence of packaging attributes on consumer evaluation of fresh cod, Food Quality and Preference, 60, 9-18.

Hung, Y.H. (2007). Optimal process parameter design for a wire bonding of ultra-thin CSP package based on hybrid methods of artificial intelligence, Microelectronics International, 24(3), 3-10.

Ishrat, S.I., Khan, Z.A., Siddiquee, A.N., Badruddin, I.A., Algahtani, A., Javaid, S., \& Gupta, R. (2019). Optimising parameters for expanded polystyrene based pod production using Taguchi method, Mathematics, 7(9), 847.

Jiang, L., Walczyk, D., McIntyre, G., \& Chan, W.K. (2016). Cost modeling and optimization of a manufacturing system for mycelium-based biocomposite parts, Journal of Manufacturing Systems, 41, 8-20.

Jin, Y., Du, J., \& He, Y. (2017). Optimization of process planning for reducing material consumption in additive manufacturing, Journal of Manufacturing Systems, 44(1), 65-78.

Jou, Y.T., Lin, W.T., Lee, W.C., \& Yeh, T.M. (2014) Integrating the Taguchi method and response surface methodology for process parameter optimization of the injection molding, Applied Mathematics \&
Information Sciences, 8(3), 1277-1285.

Kamaruddin, S., Zahid, A.K., \& Foong, S.H. (2010). Application of Taguchi method in the optimisation of injection moulding parameters for manufacturing products from plastic blend, International Journal of Engineering and Technology, 2(6), 574-580.

Karna, S.K., Singh, R.V., \& Sahai, R. (2012). Application of Taguchi method in Indian industry, International Journal of Emerging Technology and Advanced Engineering, 2(11), 387-391.

Karimi, P., Mahdieh, O., \& Rahmani, M. (2013). The study of relationship between packaging elements and purchase behaviour-consumers of good, cosmetics and health products, Interdisciplinary Journal of Contemporary Research in Business, 5(3), 281-295.

Kang, J., \& Hadfield, M. (2001). Parameter optimization by Taguchi methods for finishing advanced ceramic balls using a novel eccentric lapping machine. Proceedings of the Institution of Mechanical Engineers, Part B, Journal of Engineering Manufacture, 215(B1), 69-78.

Kirby, E.D. (2006). A parameter design study in a turning operation using the Taguchi method, The Technology Interface, 1-14.

Kumar, D., \& Kumar, S. (2015). Process parameters optimisation for HDPE material in extrusion blown film machinery using Taguchi method, IOSR Journal of Mechanical and Civic Engineering, 12(4), 1-3.

Kumar, D., \& Pandey, K.N. (2015). Optimisation of the process parameters in generic thermal barrier coatings using the Taguchi method and Grey-relational analysis, Proceedings of the Institution of Mechanical Engineers, Part L: Journal of Material Design and Applications, 231(7), 600-610.

Kumar, D., Gupta, A.K., Chandna, P., \& Pal, M. (2015). Optimisation of neural network parameters using Grey-Taguchi methodology for manufacturing process applications, Proceedings of the Institution of Mechanical Engineers, Part C: Journal of Mechanical Engineering Science, 229(14), 2651-2664.

Li, W., Hu, S.J., \& Cheng, S.W. (2002). Robust design and analysis for manufacturing processes with parameter interdependency, Journal of Manufacturing Systems, 21(2), 93-100.

Lindeke, R.R., \& Liou, Y.H.A. (1989). Methods for optimisation in the manufacturing system the Taguchi method: An engineering approach to its implementation, Journal of Mechanical Working Technology, 20, 205-218.

McMillin, K.W. (2017). Advancements in meat 
I.O. Fagbolagun and S.A. Oke

packaging, Meat Science, 132, 153-162.

Mehat, N.M., Kamaruddin, S., \& Othman, A.R. (2014). Hybrid integration of Taguchi parameter design, Greyrelational analysis, and principal component analysis optimisation for plastic gear production, Chinese Journal of Engineering, 2014, 1-11.

Nyemba, W.R., \& Mbohwa, C. (2017). Process mapping and optimization of the process flows of a furniture manufacturing company in Zimbabwe using machine distance matrices, Procedia Manufacturing, 8, $447-$ 454.

Park, M.S., Cho, J.C., Kim, S.H., Shin, D.J., Jung, H.M., Lee, C.K., Cho, M.S., \& Lee Y. (2011). Optimisation of desmear process for high adhesion of insulating film in printed circuit boards (PCBs) via Taguchi method, International Journal of Adhesion and Adhesives, 31(6), 466-472.

Patnaik, A., Satapathy, A., Mahapatra, S.S., \& Dash, R.R. (2008). Implementation of Taguchi design for erosion of fibre-reinforced polyester composite systems with $\mathrm{SiC}$ filler, Journal of Reinforced Plastics and Composites, 27(10), 1093-1111.

Pattnaik, S., Karunakar, D.B., \& Jha, P.K. (2013). Influence of injection process parameters on dimensional stability of wax patterns made by the lost wax process using Taguchi approach, Proceedings of the Institution of Mechanical Engineers, Part L: Journal of Materials: Design and Applications, 227(1), 52-60.

Patyal, V.S., Modgil, S., \& Maddulety, K. (2013). Application of Taguchi method of experimental design for chemical process optimisation: A case study, AsiaPacific Journal of Management Research and Innovation, 9(3), 321-328.

Pour, G.T., \& Moghadam, S.M.M. (2014). Optimisation of nano-calcium carbonate production process using Taguchi method, International Journal of Materials, Mechanics and Manufacturing, 2(1), 77-80.

Ramakrishnan, R., \& Arumugam, R. (2013). Optimization of cooling tower performance analysis using Taguchi method, Thermal Science, 17(2), 457470 .

Reddy, V.V., Valli, P.M., Kumar, A., \& Reddy, C.S. (2015). Multi-objective optimization of electrical discharge machining of PH17-4 stainless steel with surfactant-mixed and graphite powder-mixed dielectric using Taguchi-data envelopment analysisbased ranking method, Proceedings of the Institution of Mechanical Engineers, Part B: Journal of Engineering Manufacture, 229(3), 69-80.

Renerre, M., \& Labadie, J. (1993). Fresh red meats packaging and meat quality, Proceedings of the $39^{\text {th }}$ International Congress of Meat Science and Technology, 361-387, 1-6 August, Calgary, Canada.

Sankaran, V.S., Segar, V., Subramanian, B., \& Krishna, A. (2015). Optimization of manufacturing process parameters using Arena Simulation and Taguchi method, International Journal of Mechanical Engineering and Robotics Research, 4(1), 435-444.

Sibalija, T., Majstorović, V., \& Soković, M. (2011). Taguchi-based and Intelligent Optimisation of a multiresponse process using historical data, Journal of Mechanical Engineering, 57(4), 357-365.

Silayoi, P., \& Speece, M. (2007). The importance of packaging attributes: A cojoint analysis approach, European Journal of Marketing, 41(11-12), 14951517.

Sousa, M.R.S., Lora-García, J., López-Pérez, M.F., Santafé-Moros, A., \& Gozálvez-Zafrilla, J.M. (2020). Operating conditions optimization via the Taguchi method to remove colloidal substances from recycled paper and cardboard production wastewater, Membranes, 10(8), 170.

Steenis, N.D., Herpen, E., van der Lans, I.A., Ligthart, T.N., \& van Trijp, H.C.M. (2017). Consumer response to packaging design: The role of packaging materials and graphics in sustainability perceptions and product evaluations, Journal of Cleaner Production, 162, 286298.

Sukthomya, W., \& Tannock, D.T. (2005a). Taguchi experimental design for manufacturing process optimisation using historical data and Neural Network process model, International Journal of Quality and Reliability Management, 22(5), 485-502.

Sukthomya, W., \& Tannock, J. (2005b). The optimisation of neural parameters using Taguchi's design of experiments approach: An application in manufacturing process modeling, Neural Computing and Application, 337-344.

Tsai, C.S., \& Mort, N. (1996). Simulation and optimisation in manufacturing systems using Taguchi methods, UKACC International Conference on Control'96 (Conf. Publ. No. 427), 2-5 September, Exeter, UK.

Üstüntağ, S., Şenyiğit, E., Mezarcıöz, S., \& Türksoy, H.G. (2020). Optimization of coating process conditions for denim fabrics by Taguchi method and Grey relational analysis, Journal of Natural Fibers, 17.

Verbeke, W., De Smeo, S., Vackier, I., Van Oeckel, M.J., Warnats, N., \& Van Kenhove P. (2005). Role of intrinsic search cues in the formation of consumer 
preferences and choice for pork chops, Meat Science, 69(2), 343-354.

Wazed, M.A., Ahmed, S., \& Nukman, Y. (2010). Application of Taguchi method to analyse the impacts of commonalities in multistage production under bottleneck and uncertainty, International Journal of the Physical Science, 5(10), 1576-1591.

Xydas, N., Tsi, D., Gurevich, V., Krichever, M., \& Kao, I. (2005). Dynamic Taguchi methods and parameter design as applied in barcode scanning and scanners, Concurrent Engineering, 13(1), 69-80.

Zagloel, T.Y., \& Al-Aina, F. (2009). Gram optimisation using Taguchi method of parameter design and neural network process model in packaging industry, 2nd Asia Pacific Conference on Manufacturing System 45 November, Yogyakarta, Indonesia, 9-16. 
This page is intentionally left blank 